\title{
ANAESTHETIC MANAGEMENT OF SEVERE INJURIES
}

R. G. B. GILBERT, M.B., F.R.C.P. (C), F.F.A.R.C.S.

MANY CENTRES now have trauma or accident services to which there is usually cppointed an anaesthetist as a member of the resuscitation team. This position is one of great interest, which needs both experience and initiative if the mortality of our high accident rate is going to be reduced. This area is one where teamwork among the various members of the surgical specialties and the resuscitation personnel is of great importance.

Although traffic accidents are responsible for many serious injuries; figures trom the Dominion Bureau of Statistics demonstrate that other fields are also productive. Table I gives the number of accidents with fatal qutcome during the

TABLE I

COMparative SEmmars

(from Dominion Bureau of Statistics, June 30, 1960)

\begin{tabular}{|c|c|c|c|}
\hline & \multicolumn{3}{|c|}{ Canadd } \\
\hline & 1957 & 1958 & 1959 \\
\hline \multirow{2}{*}{\multicolumn{4}{|c|}{ Vumber of acudents: }} \\
\hline Fatal (renulting in the death of one or more persons) & & & 2,763 \\
\hline Don-fatal (resulting in the injury of one or more persons) & 54,036 & 54,576 & 57,202 \\
\hline Resulting in property damage only (\$100) or over & 163,835 & 170,202 & 182,461 \\
\hline Total number of accidents & 220,672 & 227,451 & 242,429 \\
\hline Persons killed & 3,260 & 3,118 & 3,231 \\
\hline Persons injured & 78,426 & 80,061 & 84,751 \\
\hline lotal property damage* (thousando of dollars) & 73,123 & 72,825 & 78,706 \\
\hline
\end{tabular}

Exsluder bueber

years 195i, 1958, and 1959; Figure 1 shows the dominant role of motor vehicle and home accidents; Figure 2 tabulates all non-transport accidents; and Figure 3 examines the causes of home accidents.

\section{Manageatent}

This may be discussed under the following headings:

1. Careful assessment: $(a)$ injuries: single, multiple, and complicated; $(b)$ "shock"; $(c)$ pre-existing disease; $(d)$ drug therapy

2. Relief of pain and replacement of blood and fluid.

3. Handling of patients.

4. Anaesthetic management.

5. Postanaesthetic management: (a) respiratory; $(b)$ cardiovascular; $(c)$ acid base; $(d)$ kidneys.

*Department of Anaesthesia, McGill University, Montreal. 


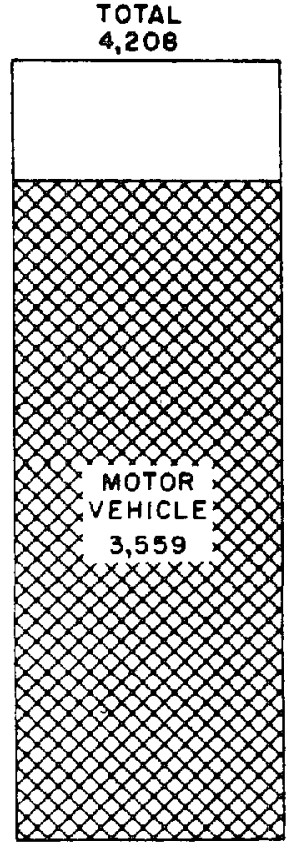

TRANSPORT

ACCIDENTS
TOTAL

4,992

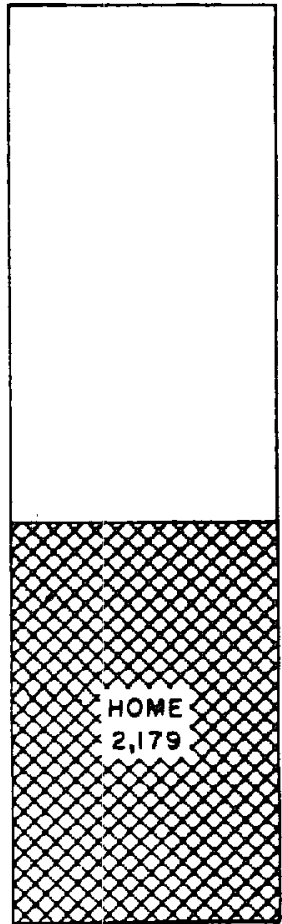

NON-TRANSPORT ACCIDENTS

Figure 1. Motor vehicles and the home dominate accident mortality.

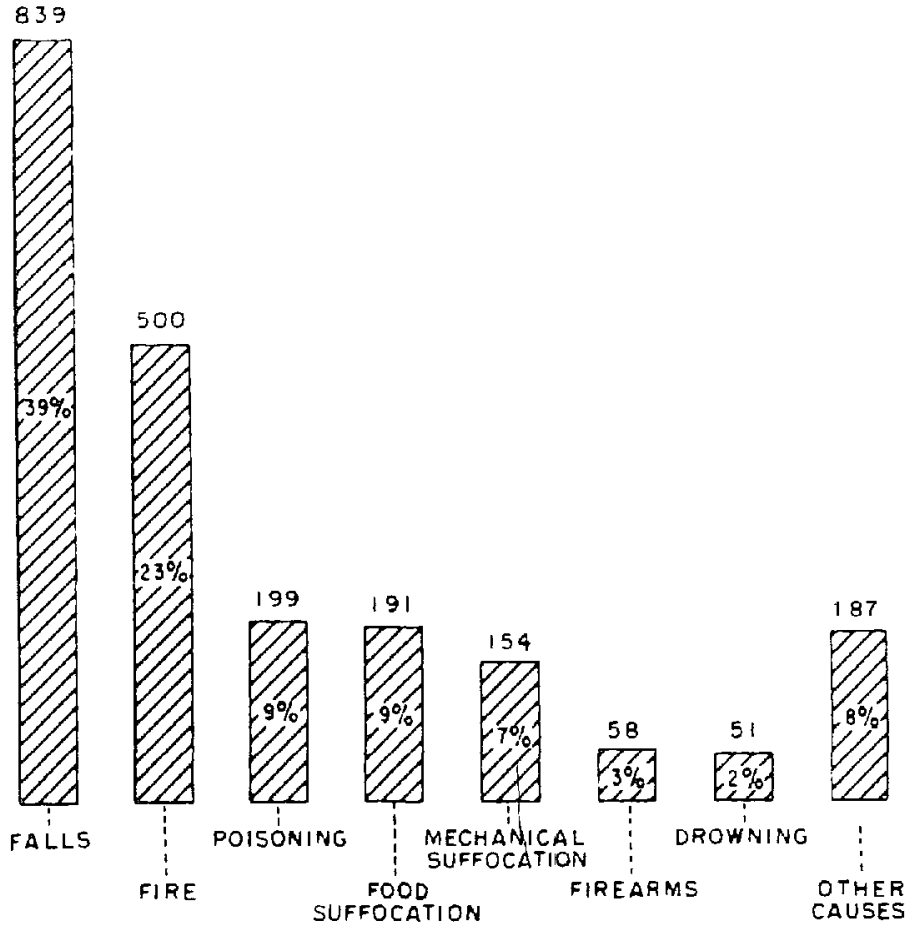

Figure 2. Leading causes of home accidents, 1956. Number and percentage of accidental home fatalities. 
HOME

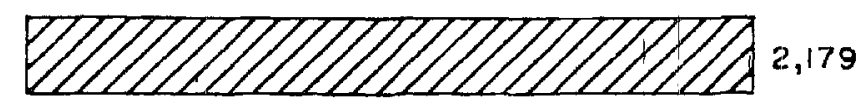

FARM

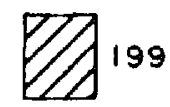

MINE AND QUARRY

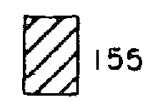

INDUSTRY

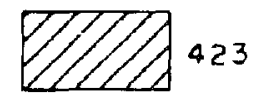

PLACE FOR
RECREATION

22

STREET

FIGURE 3. Home locations predominate in specified non-transport accidents.

\section{Assessment}

The initial assessment is of the greatest importance and urgency. To start with, it is based upon the clinical examination. Time lost may mean a life lost; the $\mathrm{X}$-ray examination of a patient with a fractured femur who also has a tension pneumothorax may be disastrous.

During the First World War, the cardiovascular state of casualties, the degree of "shock," was evaluated clinically, which resulted in their division into three categories: compensated, partially compensated, and uncompensated. Little attention was paid to this concept up to the Second World WVar, when similar groups were classified according to blood pressure, pulse, and clinical evaluation. However, during the Second War, other groups presenting different cardiovascular responses were noted, such as hypertensive cases, those who were cold, those who were warm, those who were pale, and those who were cyanosed in spite of a good airway. In a Field Surgical Unit in northwestern Europe there was opportunity to differentiate clinically between some of these entities and to observe the response to multiple transfusions, though there was relative darkness as to why there were differences.

Grant $^{1}$ in 1951 suggested different patterns of circulatory response to trauma: normal, cold tachycardia, warm tachycardia, hypertensive, vasovagal, cold hypotensive, and warm hypotensive, the criteria being blood pressure, pulse rate, temperature of the limbs, and colour.

Simeone $^{2}$ has described the close correlation between this clinical type of evaluation of wound shock and that deduced from physiological and biochemical data.

Beecher $^{3}$ differentiated the pain response to injury between soldiers and 
civilians. The severely wounded soldier feels assured of a "Blighty One" and can expect relief from front-line action whereas a severely injured civilian may face disturbing domestic problems. The soldier is physically fit, whereas the civilian is not necessarily so.

With this background in mind, it should be possible to make a sound clinical assessment of the general condition of a severely injured patient and to control his pain and psychic trauma. The degree of circulatory insufficiency must be estimated and the presence of an unobstructed airway assured, with adequate ventilation. It might be worthy of note concerning this latter that Schmidt ${ }^{4}$ has pointed out that in a German hospital centre where road accident victims are taken, of those dead on admission the pathologist reported that 60 per cent had died from asphyxia. This in itself most forcibly suggests the correction of one of the major problems.

While the immediate assessment and preliminary, sometimes life-saving, treatment is being carried out, surgical members of the team investigate the local injuries. All should be aware of possible evidence of pre-existing disease and recent drug therapy, both or either of which mily suggest modification in the measures subsequently to be adopted. Almost in the same category come excessive indulgence in alcohol and the eating of a recent meal.

Although the local problems are the province of various surgical specialties, the anaesthetist should be familiar with all those which might affect the general condition of the patient or influence his specific sphere.

\section{Relief of Pain and Blood or Fluid Replacement}

The effects of pain and fear on the seriously injured were two of the earliest aspects of this problem to receive thought and consideration from both physicians and philosophers. The anaesthetist, by virtue of his training, is able to use a variety of drugs which act at different levels of the pain pathways or which may alter the perception of pain, be they narcotics, ataractics, or, less commonly, hypnotics. He may need to use an anaesthetic agent or utilize a nerve-block procedure to control pain or facilitate manipulation.

By considering the effects of drugs and anat'sthetic procedures upon metabolism and tissue homoeostasis, the anaesthetist is in a good position to control this part of the problem.

The necessity for blood replacement in those with severe injuries is accepted by all, but the complications of this treatment are being realized more and more. For instance, the metabolic acidosis that occurs in some of these cases may be magnified by the rapid infusion of citrated blood. This suggests the possible use of buffers. Such acidosis may cause cardiac arrest, which may also be precipitated by the cold temperature of the blood used in rapid multiple transfusions, or from the hyperkalaemia resulting from liver anoxia ${ }^{5}$ and transfused blood. The possibility of citrate intoxication has in the past received much publicity. Though not as important as was originally believed, it may still play a role in the production of myocardial depression, and so should be corrected.

Millar, ${ }^{6.7 .8}$ working in our laboratory, has estimated the rising levels of circulating catecholamines and the arterial $\mathrm{pCO}_{2}$ with lowering of blood $\mathrm{pH}$ following 
haemorrhage both in the intact and adrenalectomized dog and in those pretreated with either phenoxybenzamine or chlorpromazine. In spite of the fact that norepinephrine may increase the cardiac output, this does not appear to follow; neither is its use clinically always promising. It may be that the correct $\mathrm{pH}$ is necessary for its optimum action. This fact should prompt us to conşider the $\mathrm{pH}$ in shocked cases, especially those resistant to vasopressor therapy, if such has been used.

Nickerson ${ }^{9}$ and others advocate that adrenergic blockade be induced in severely injured patients in shock, believing thereby that the bloorl pressure, once normovolaemia is attained, is gradually restored and urinary output improved. This consideration may also be of value in forms of septic shock, pressumably by limiting portal venoconstriction.

In view of the importance of the use of balanced salt solutions in shock, the usefulness of particular electrolyte solutions to be given was emphasized by Rhoads $^{10}$ in a summation of the Conference on Shock in December 1960. Acidosis must be corrected and fluid and electrolytes replaced; whether this is most ideally done with Ringer lactate, sodium bicarbonate, or buffer solutions investigators will tell us. This is especially important in severely burned patients, and following surgery of the severely injured.

\section{Handling of Patients}

By this, reference is made to the physical effects of the examination, manipulations, and transfer of patients to different areas of the hospital. Patients who are severely injured may lack the efficiency of their own vascular reflexes. Careless moving and posturing may then result in further depression of the circulation. Though some gravely injured patients, curiously, have little pain, others suffer greatly, and this may be accentuated by rough handling, thereby increasing stress and psychic trauma. Too vigorous examination may complicate a fracture, producing for example a pneumothorax, or even haemopericardium. Moving patients with unsplintered fractured limbs may give rise to fat embolus. This is more likely to occur in a patient who is unconscious, for he may not resist examination, or his spasms may promote it.

\section{Anaesthetic Management}

Whatever type of anaesthetic is administered to these patients, there must be full assurance that ventilation is optimal. The patient's organs and tissues are potentially, if not actually, hypoxic and acidotic, neglect of this principle will further impair their condition.

Agents such as cyclopropane, ether, and thiopentone exhibit a marked sympatho-adrenal response; in contradistinction, Millar ${ }^{11}$ has shown that: "During uncomplicated halothane anaesthesia no significant increase or "decrease in adrenalin or noradrenalin could be measured." However: "Elevation of arterial $\mathrm{pCO}_{2}$ was accompanied by significant rises in plasma catecholamine levels; mean arterial blood pressure was reduced during hypercarbia. Haemorrhage induced variable increases in adrenalin, with less effect on noradrenalin." The same, he showed, is true of methoxyflurane. 
The advantages of using light cyclopropane or ether are the high oxygen content of the inhaled mixture and the maintenance of blood pressure at a high or even exaggerated level. However, fostering the already existing vasoconstriction may not be desirable. More recent impressions suggest that halothane is to be preferred, in that the blood flow to and perfusion of vital organs is increased, despite a fall in blood pressure, provided the patient is normovolaemic. The advantages of halothane find sponsorship in the work of Nickerson, which has already been mentioned.

Experience has shown that thiopentone, except in minimal doses, is not a wise choice on account of its myocardial depressant action and that if a spinal or epidural blockade is used there must also be support to both ventilation and circulation.

Whatever agents are used, they should be given in minimal quantities for any particular purpose. The haemodynamics of shocked patients are altered in suoh a manner that a high circulating concentration of inhalation agents rapidly occurs. ${ }^{12}$

In our hands no harm has appeared to come from curarizing many of these patients, thereby enabling efficient ventilation to be carried out under very light anaesthesia. If a patient is already unconscious, from a head injury, ventilation with 40 per cent oxygen under curarization is eminently satisfactory.

There may be indications for nerve-block anaigesia. These will be dictated by the particular site of the injury and the degree of manipulation necessary to perform the procedure.

The anaesthetic management includes further blood and fluid replacement, if necessary, and intelligent monitoring. Much can be determined by constant observation of pulse, blood pressure, minute volume, capillary return, the colour of the patient, and the temperature. It is a useful asset if blood $\mathrm{pH}$ determinations, arterial gas studies, and bicarbonate level determinations can also be made from time to time. These figures not only are of significance during the operation, but also serve as base-line values for the period of postoperative care, as also, of course, may initial reports of biochemical and haematological nature.

Although the myth of chlorpromazine has been to a great extent exposed, there is no doubt that occasionally a good response may be obtained by the inclusion of this type of drug either alone or in combination with other drugs.

As well as anaesthetic drugs, the anaesthetist should be familiar with the possible indications for and mode of action of vasopressor drugs.

\section{Postanaesthetic Management}

During the phase immediately following operation, the patient may still be regarded as under the influence of anaesthesia. The metabolic effects of the agents used are still present, and respiration and circulation may still be depressed, as the result not only of the injury but also of the subsequent anaesthesia and surgery. Controlled intravenous therapy and analgesia may be necessary. In some cases assistance to respiration, via either an endotracheal tube or a tracheotomy, may be needed.

In later stages, treatment is given according to the patient's reactions to 
stress, the tissue trauma, pain, infection, blood and fluid loss, and his responses to altered metabolism and fluid and electrolyte balance. From a practical standpoint such a regime may conveniently be aimed at the respiratory system, the heart, the acid/base balance, and the kidney; imbalance in each one may affect the others. For details of care and regulation of the latter two, reference is made to the monumental work of Francis D. Moore, ${ }^{13}$ Metabolic Care of the Surgical Patient.

It is natural that the major responsibility for this period should be that of the surgical group, but the addition of an anesthetist to this team may be most helpful. In some centres and under certain circumstances, such as when hypothermia is used, even more may be demanded of him; he must then be familiar with the day-to-day reports of fluid intake and output, blood gas analysis, and biochemical data.

\section{Types of Severe INJuRIES}

These can be summarized.under the following: head injuries; head injuries and associated injuries, e.g. crushed chest; spinal injuries; spinal injuries and associated injuries; chest injuries: tamponade, pneumothorax, haemothorax, collapse of lung, pneumonitis, mediastinal emphysema; abdominal injuries (not forgetting the uterus ); genito-urinary injuries; facial injuries; burns.

\section{Head Injuries}

Patients with severe head injuries frequently show few signs of circulatory depression. This may be because they are unconscious and thereby free from pain, fear, and possibly stress, or because they have not suffered severe haemorrhage.

It may be that the injury has in some way prevented the generalized vasoconstriction associated with the circulatory failure of the severely injured individual. Many patients in this category have been reported to be hypervolaemic. A patient with a head injury, who is also in a state of severe collapse, may have an associated injuxy.

Case 1. To illustrate a serious head injury, the case of a 23-year-old man can be given. While playing Russian Roulette, he shot himself through the mouth, the exit wound being in the parieto-occipital area, just off the mid-line. Prior to operation, his circulation appeared normal but his respiration presented marked hyperventilation. This might have been caused by the head injury or by the fact that he had a chest full of blood which he had aspirated. He was unconscious but not decerebrate. While he was being prepared for operation, the blood $\mathrm{pH}$ and gases were estimated. The $\mathrm{pH}$ was 7.09, oxygen saturation 97.6 per cent, and $\mathrm{PCO}_{2} 56.5 \mathrm{~mm}$. $\mathrm{Hg}$. These figures enabled alkalinization to be undertaken, after which his $\mathrm{pH}$ rose rapidly to 7.2 . Anaesthesia consisted of curare administration and ventilator care following endobronchial toilet. Following the operation, the respiration was markedly improved. The patient was cooled to $28^{\circ} \mathrm{C}$. and kept hypothermic for several days before emergence and reasonable recovery. During this period observations were made of the vital signs, fluid intake and output, blood $\mathrm{pH}$ and gases, minute volume, biochemical and haematological data, including serum osmolarity and the electrophoretic pattern. 
Case 2. Head injury with associated injuries may be exemplified by the case of a 28-year-old woman who was involved in an automobile accident in which she last her husband and only child. Her injuries amounted tö: a basal skull fracture, fractures of the mandible on both sides and the maxilla on one side, the odontoid process and C.2, ribs 1,2,3,4, and 5 on the left and 1,2, and 3 on the right, the left femur into the knee joint and the left os calcis, the right ankle, and a number of metatarsals.

Her chest was the most immediate problem and handling for X-ray,purposes presented difficulties. On the left side of her chest she had a haemothorax, while on both sides there were areas of traumatic pneumonitis. A tracheotomy was performed so that controlled and later assisted respirations e:isured ventilation. While she was still unconscious, skull tongs were used to fix her spine and temporary casts applied to control her legs. The nursing problem was extreme so she was placed on an alternating inflatable mattress. She never developed any sores. The haemothorax resolved following treatment by closed drainage, but a staphylococcal infection was superimposed on the atelectatic areas, producing widespread staphylococcal bronchopneumonia.

Ventilation, fluid, and electrolytes were handled in a manner similar to that used in the previous case until consciousness was regained and tube feeding initiated. Before her eventual fecovery she developed a tracheo-oesphageal fistula which later needed plastic reconstruction.

\section{Spinal Injuries}

These do not usually present immediate difficulties from the anaesthetic standpoint, but it is sometimes wise to anaesthetize these cases for, and always to handle them carefully during, X-ray examination. Subsequent bladder care and nursing attention is all-important. The cases which do extend the efforts of the anaesthetist are those of high cervical injuries in stout individuals. These nearly always need respiratory assistance and monitoring, while the presence of an ileus may tax the surgeons. From a technical viewpoint, such cases are better intubated awake by the nasal route under local anaesthesia. A tracheotomy can later be performed.

A spinal injury in association with other injuries is characterized by the following case.

Case 3. A 35-year-old woman who was transferred from another hospital ten hours

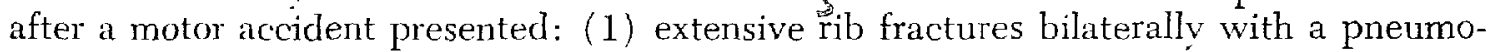
thorax and a haemopneumothorax; (2) paralvsis up to the lower thoracic area resulting from fractures of T.10 and 11 (there was evidence of an old fracture of T.5 with consequent hyphotic deformity); (3) at a subsequent date it became apparent that she had a drug in ithdrawal reaction, as she was discovered to be a chronic alcoholic.

Clinical examination proved the gravity of her chest condition, and in addition an $X$-ray demonstrated traumatic pneumonitis. The pleural cavities were tapped and sealed under water before an extensive laminectomy was performed under fluothane, nitrous oxide, and curare, ventilation being carried out automatically. Following the operation, a tracheotomy was performed and she did well for the first day. She then became restless and cyanosed. Blood gas studies revealed unsaturation to a level below 70 per cent with only mild hypercarbia, indicating a diffusion defect. Heavy sedation and ventilator care brought her blood gases to niormal, but she was unable to be transferred to assisted respiration owing to delirium tremens. More sedation, including promazine, alcohol, paraldehyde, and sparine eventually settled her, but for some time spontaneous unassisted respiration was not effective in saturating her. It was not until the third week that her ventilation approached normal. 


\section{Chest Injuries}

Chest injuries are now commonly cared for, in major centres, by a thoracic team with the assistance of an anaesthetist to ensure adequate ventilation and relief of pain, and to monitor the $\mathrm{pH}$ and blood gases.

Pneumothorax, tension pneumothorax, haemothorax, collapse of the lung, traumatic pneumonitis, oedema of the lungs, mediastinal emphysema, and cardiac tamponade are some of the injuries and sequelae that can occur.

\section{Abdominal Injuries}

Abdominal injuries are frequently associated with blood loss. There are not infrequently injuries to the genito-urinary system as well. Careful assessment and replacement therapy is essential; in spite of this, immediate operation may have to be planned.

Possible injuries to the pregnant uterus may add to the confusion of damaged spleen or liver. The following casse will illustrate this point.

Case 4. A patient about eight months pregnant was involved in an automobile accident. She did not at first appear to be severely injured, but was taken to the accident service for observation. Because of her pregnancy and since she was not considered severely injured, she was taken to the obstetrical department but returned later, when it was thought that she had suffered injury to her hij and not to the uterus or the infant. A dislocated hip was reduced under general anaesthesia. Following this she became faint and a state ot semiconsciousness supervened. Central nervous system examination revealed the possibility of inequality of the pupils, so she was referred for neurosurgical consultation. By the time of her arrival in the X-ray department it appeared obvious that she had blood loss, and she was rapidly transfused as soon as the blood was available. The skull films demonstrated a sublural haematoma. Craniotomy was performed while she was still anaesthetized. During this her condition deteriorated in spite of the transfusion of more blood. Both she and the infant clied shortly after. Autopsy revealed a ruptured spleen.

\section{Other Injuries}

Gross limb and bladder injuries need special surgical care; except for the circulatory condition of the patient, they do not present any specific anaesthetic problems.

Facial injuries may be difficult in view of the obstructed airway, especially during transportation. Tracheotomy on admission is a priority.

The treatment af severe burns is not within the bounds of this presentation but the anaesthetist may be confronted with a number of problems. Initially those due to shock, pain, stress, and fluid loss must be met. Burns involving the head and face are most grave while those, especially in children, involving the anterior surface of the chest are frequently associated with pulmonary complications. Fluid and electrolyte balance is of immense importance if lower nephron nephrosis is to be avoided.

Anaesthesia may be required on successive occasions and should be as simple as possible. Intubation following succinylcholine, and especially a second dose, in infants and children with extensive infected burns requiring skin grafting in the later stages may give rise to cardiac arrest. Therefore careful preoperative examination is essential. ${ }^{14}$ 


\section{Fat Embolism}

Sproule ${ }^{15}$ recently summarized the clinical features of fat embolism from cases which he has studied, occurring in those with fractures, severe injuries, and burns. The common factors which he stressed were mental changes, petechiae, anaemia, pulmonary infiltration, elevation of serum lipase, fall in serum calcium, fat in sputum or urine, diminished oxygen saturation without cyanosis, diminished vital capacity, and increase in plasma haemoglobin. To this list might be added fever, headache, tachycardia, and the detection of large fat droplets in the serum. Not all of these signs and symptoms need necessarily be present at the same time. The hypoxia may possibly be due to a diffusion defect, shunt, or alteration in the surface tension in the alveoli while the lack of cyanosis in these cases also causes speculation. There is anaemia, which is not necessarily gross; there is probably increased cardiac output while the dilatation of the peripheral vascular bed, sometimes seen, may produce a sufficient arterialization of venous blood to prevent the appearance of cyanosis. In definite cases of fat embolus, the total ventilation is increased while the alveolar ventilation is decreased; the carbon dioxide tension is within normal limits.

The fact that fat embolism may occur in association with conditions other than fractures and the fact that the simple classical explanation is not altogether satisfactory has led to much research in recent years. The anaesthetist should be familiar with various theories, the diagnosis, and possible lines of treatment of this condition.

\section{Special Techniques}

Controlled ventilation has been alluded to a number of times. It is by far the most effective method of adequately ventilating a patient. It may require full curarization or extreme sedation to stop partial, ineffective, spontaneous respiratory efforts. It will require constant monitoring to ensure maintenance at the full value.

Hypothermia has a place in the treatment of head and other serious injuries but what exactly this position is, no one as yet can define. It is certain that some cases have survived because of it; some of these would probably have survived without it, but some who did not receive this form of care might have survived had they received the benefit of it. It is unfortunately also true that of those who have been salvaged, many no longer have intellectual power, while many others have some physical deficit. A Hungarian worker ${ }^{16}$ has reported 5,000 paediatric cases treated by hypothermia and blocking agents, the latter in a very rational manner.

The administration of a continuous epidural anaesthetic under certain conditions is a useful method for control of pain. It may play a role in the treatment of renal failure. It may also be a valuable technique to employ when the chest has been crushed, relieving pain and facilitating automatic ventilation. 


\section{SUMMARY}

The anesthetist's knowledge of ventilation and circulation, of fluid and electrolyte requirements, and his association with the use of potent depressant and stimulant drugs, place him in a position to use his ability in a worth-while manner in the care and treatment of severe injuries.

\section{RÉSUMÉ}

Dans la conduite à tenir en présence de grands blessés, l'auteur insiste sur cinq points principaux. D'abord, l'évaluation sérieuse de l'état du malade: il faut se rendre compte si la blessure est simple, multiple ou compliquée; s'il y a état de choc; si. le blessé souffrait de maladies avant son accident et s'il avait reçu récemment des traitements médicamenteux. Deuxièmement, il insiste sur l'importance de soulager la douleur et de remplacer les pertes de sang et de liquides. Troisièmement, il traite des précautions à prendre dans la manipulation de ces malades. Quatrièmement, il donne son opinion sur l'anesthésic telle qu'elle doit être administrée aux grands blessés. Enfin, il insiste sur les soins post-anesthésiques, surtout en regard de la respiration, de la circulation, de l'équilibre acide-base et des reins.

En complément, il s'arrête à certains types de blessures graves, soit les blessures de la tête, simples ou associées, les blessures de la colonne vertébrale, simples ou associées, les blessures du thorax, de l'abdomen, des organes génito-urinaries, de la face, et enfin les brûlures. Il cite quelques techniques spéciales qui peuvent, à l'occasion, rendre de grands services, soit la ventilation contrôlée, l'hypothermie et l'épidurale continué.

\section{REFERENCES}

1. Grant, R. T. Symposium on Shock. Washington, D.C.: Army Medical Services, Graduate School, Army Medical Center (1951).

2. Simeone, F. A. Fed. Proc. 20, No. 2, Pt. in, Supp. 9: 3 (1961).

3. Beecher, H. K. Measurement of Subjective Responses, pp. 164-165. London: Oxford University Press (1959).

4. Schmwt, H. Personal Communication.

5. Bunker, J. P. et al. New Eng. J. Med. 266: 372 (1962).

6. Mirlan, R. A. \& Benfex, B. G. Brit. J. Anaesth. 31: 258 (1959).

7. Millar, R. A.; Keener, E. B.; \& Benfey, B. G. Brit. J. Pharmacol. 14: 9 (1959).

8. Millar, R. A. \& Benfey, B. G. Brit. J. Anaesth. 31: 258 (1959).

9. Nickerson, M. \& Earter, S. A. Can. J. Biochem. 37: 1161-1171 (1959).

10. Rroans, J. E. Fed. Proc. 20, No. 2, Pt. III, Supp. 9: 235 (1961).

11. Millar, R. A. \& Morris, M. E. Canad. Anaesth. Soc. J. 7: 423 (1960).

12. Drupps, R. D. Fed. Proc. 20, No. 2, Pt. iII, Supp. 9: 224 (1961).

13. Moore, F. D. Metabolic Care of the Surgical Patient. Philadelphia: Saunders (1959).

14. McCaughey, J. S. Canad. Anaesth. Soc. J. 9: 220 (1962).

15. Sproule, B. Western Div. Canada. Anaesth. Soc. Meeting (March, 1962).

16. Veghelyi, P. V. J. Ped., St. Louis 60: 122 (1962). 